Elsevier required licence: (C) <2019>. This uncorrected proof version is made available under the CC-BY-NC-ND 4.0 license

http://creativecommons.org/licenses/by-nc-nd/4.0/ 


\title{
Algorithmic management: The case of Airbnb
}

\author{
Mingming Cheng ${ }^{\mathrm{a}}$ *, Carmel Foley ${ }^{\mathrm{b}}$ \\ a School of Marketing, Curtin Business School, Curtin University, Australia \\ ${ }^{\mathrm{b}}$ University of Technology Sydney, UTS Business School, Ultimo, NSW, 2007, Australia
}

\section{ARTICLE INFO}

\section{Introduction}

Algorithmic management as a new trend in tourism and hospitality has received significant media attention in recent years. Datification in the tourism and hospitality sector has created new opportunities for business strategy and growth for many organizations. Algorithms are being used to aggregate and analyse data, contributing to the decision-making process (Newell and Marabelli, 2015). The process goes beyond simple analytics and has replaced some of the tasks that are traditionally managed by human beings, particularly those within the boundary of middle managers (Jarrahi and Sutherland, 2018). However, academic research on algorithmic management and its implications for tourism and hospitality providers, consumers and prosumers is still in its infancy.

Digitization of the tourism and hospitality sector combined with the emergence of large sharing economy platforms has provided fertile ground for further tech-based innovation. Sharing economy platforms are increasingly utilizing algorithms to manage and coordinate extremely large amounts of data on both workers and customers (Yu et al., 2017); but how workers are being impacted by these relatively new algorithmic management practices remains unclear. This research note focuses on Airbnb which represents one of the most rapidly growing peer-to-peer platforms on the planet. The study investigates ways in which Airbnb hosts have responded and adapted to algorithmic management practices employed by Airbnb. Our research is an early attempt to contribute to the emerging academic dialogue on the algorithmic turn in tourism and hospitality, and to advance academic research on human resource aspects of the sharing economy.

\footnotetext{
* Corresponding author.

Email addresses: Mingming.cheng@curtin.edu.au (M. Cheng); Carmel.foley@uts.edu.au (C. Foley)
}

\section{Algorithmic management in the sharing economy}

Algorithmic management is rapidly emerging in sharing economy platforms (Mohlmann and Zalmanson, 2017). The driving forces are business models that mobilize peer-to-peer access to under-utilized resources and the extremely large numbers of workers and clients that these platforms coordinate and manage (Yu et al., 2017). Traditionally, these sorts of management and coordination tasks are overseen by middle managers. However, due to the scale of the workforce in sharing economy platforms, algorithm-based decisions are increasingly being adopted by organisations to facilitate efficient management through automation (Jarrahi and Sutherland, 2018). Further, research evidence indicates that algorithmic management decisions outperform human management decisions in more than $80 \%$ of cases in the common workload context (Yu et al., 2017).

Algorithmic processes include matching workers and clients with the right skills and assigning tasks, as well as evaluating, penalising and rewarding workers' performance (Lee, 2016). Some of these processes require little human intervention. For example, Uber's algorithm is designed to, among other things, generate performance reports of drivers. This provides Uber with an automated panopticon of surveillance (Foucault, 2012). Effectively, the algorithm allows Uber to structure relationships of control over Uber drivers (Rosenblat and Stark, 2016). There is little doubt that algorithmic management is providing useful and effective tools for the operation of large sharing economy platforms.

What is at issue, however, is that algorithmic practices are creating new challenges in work environments for the sharing economy labour force. While some sharing economy workers are employing agility and creativity - making sense of the algorithmic management tools employed by their platform organisations and then manipulating them for personal benefit (Jarrahi and Sutherland, 2018), others are feeling 
helpless and powerless in the face of this new use of technology. Emerging evidence indicates that algorithmic management is contributing to uncertainty and anxiety for sharing economy workers in the management of their micro-businesses (Rosenblat and Stark, 2016). Further investigation into how sharing economy workers are responding to algorithmic management is critical for sharing economy operators such as Airbnb if they are to remain committed to "using technology to economically empower [the] millions" of hosts who use their platform and the "communities in which [they] operate" (Airbnb, 2018). Insights into the effects of algorithmic management on workers may help the sharing economy platforms to design more effective and efficient $h u$ man-in-the-loop algorithm-based practices that better support the small business operators they work with.

\section{Research design}

The Airbnb host online community forum was chosen as the data source. At the time of this research, there were 470,968 members with a total of 699,882 posts. Relevant discussion threads were searched using the key word "algorithm". Postings selected for analysis for further limited to those written in English. As a result, 545 postings were analysed.

The use of online forums has gained great popularity in tourism and hospitality research (Kozinets, 2010; Mkono, 2018). On-line forums provide an ideal source of data for exploratory studies and offer an "unadulterated first-person perspective" (Hookway, 2008, p. 107). The online postings were collected and thematically analysed concurrently and inductively. This process helped the researchers to iteratively identify and refine themes. Through the process, the researchers also constantly compared the identified themes with the extant literature (Jarrahi and Sutherland, 2018; Jhaver et al., 2018) as Strauss and Corbin (1998) suggest. After a few iterations, the themes were finalized. Table 1 presents the frequency of themes and a data exemplar of each theme.

\section{Findings}

Fig. 1 presents the themes identified and represents the various ways in which Airbnb hosts responded and adapted to Airbnb's algorithmic management techniques. The data indicates that Airbnb hosts' practices are being shaped by algorithmic management through penalty and rewards administered via both the platform itself and potential Airbnb guests. The whole process of algorithmic management, while creating opportunities, also presents significant challenges for Airbnb hosts.

Like it or not, Airbnb hosts have no choice but to be placed in the algorithmic environment. As such, they have to first make sense of what is algorithmically-driven, such as "smart price", review ratings, and "Superhost" status. This sense-making process is not straightforward.
Table 1

Emergent themes and data exemplars $(n=545)$.

\begin{tabular}{|c|c|}
\hline Theme (frequency) & Data exemplar \\
\hline $\begin{array}{l}\text { Algorithm ambiguity } \\
\text { (228) }\end{array}$ & $\begin{array}{l}\text { When I search for my place it doesn't show up in the search } \\
\text { result... Because last summer I was refusing some guests I } \\
\text { can even understand that Airbnb algorithms might put my } \\
\text { place by the end of the search results... But the thing is... } \\
\text { it's not showing up... and the worst part is that as soon as I } \\
\text { log in (with my user and password), my place } \\
\text { "mysteriously" shows up as the first hit in the search... }\end{array}$ \\
\hline $\begin{array}{l}\text { Sense of anxiety/ } \\
\text { frustration (160) }\end{array}$ & $\begin{array}{l}\text { After this last operational and PR nightmare change in } \\
\text { TOS, Host really need access or should be better informed } \\
\text { as to how the search algorithm works for how renters find } \\
\text { houses when looking to book on Airbnb. Consider what it } \\
\text { means if they list all Instant Books first then non-instant } \\
\text { books! }\end{array}$ \\
\hline Sense of control (33) & $\begin{array}{l}\text { The algorithm uses criteria such as the guest's search } \\
\text { history, the guest's booking history, the guest's contacts in } \\
\text { social media, the guest's age, the number of guests and } \\
\text { many other things that you cannot control. } \\
\text { So, what can YOU control? Your prices, your calendar, your } \\
\text { photos, your description text, your response rate and to } \\
\text { some extend your reviews. }\end{array}$ \\
\hline $\begin{array}{l}\text { Experimentation } \\
\text { (54) }\end{array}$ & $\begin{array}{l}\text { This leads me to suspect that airbnb's algorithms don't } \\
\text { favor hosts who use the dispute resolution system and I was } \\
\text { dropped down in the list. Worth knowing! I would hesitate } \\
\text { to use the dispute resolution system again. My bookings are } \\
\text { only just returning to their previous levels now. }\end{array}$ \\
\hline Resistance (74) & $\begin{array}{l}\text { I think what I'm saying is, I'm going to (try to) stop } \\
\text { worrying about what factors may penalise me (eg not using } \\
\text { Instant Book, declining guests - I decline a fair number) } \\
\text { and instead concentrate on doing the best I can, with what } \\
\text { I've got, because we must be doing something right. }\end{array}$ \\
\hline Manipulation (78) & Even if it's just a small change in wording it helps the \\
\hline $\begin{array}{l}\text { Airbnb penalty and } \\
\text { rewards (63) }\end{array}$ & $\begin{array}{l}\text { Airbnb algorithm to think you are staying active and } \\
\text { engaged. Try not to decline any requests and never cancel. } \\
\text { As we are all aware, Airbnb was specifically designed for } \\
\text { owners but with the recent introduction of allowing } \\
\text { agencies to advertise we feel current algorithms favour } \\
\text { owners and therefore their properties automatically rank } \\
\text { higher. }\end{array}$ \\
\hline
\end{tabular}

Due to algorithm ambiguity, Airbnb hosts often are confused about "what is actually behind" algorithmic management outcomes. While acknowledging that a certain amount of information is available, Airbnb hosts perceive that much of the information required to be able to effectively manage the algorithmic environment is largely hidden from them.

In cases where a problem was identified (for example, poor review ratings), Airbnb was often not able to identify the source of the problem. This contributed to the sense of anxiety experienced by some hosts. This anxiety increased in circumstances where Airbnb hosts perceived that the algorithm might not necessarily be accurate or work to their advantage. For example, the "smart pricing" algorithmic function of Airbnb was frequently mentioned by Airbnb hosts who were confused as to whether they should follow it or not, as sometimes the results

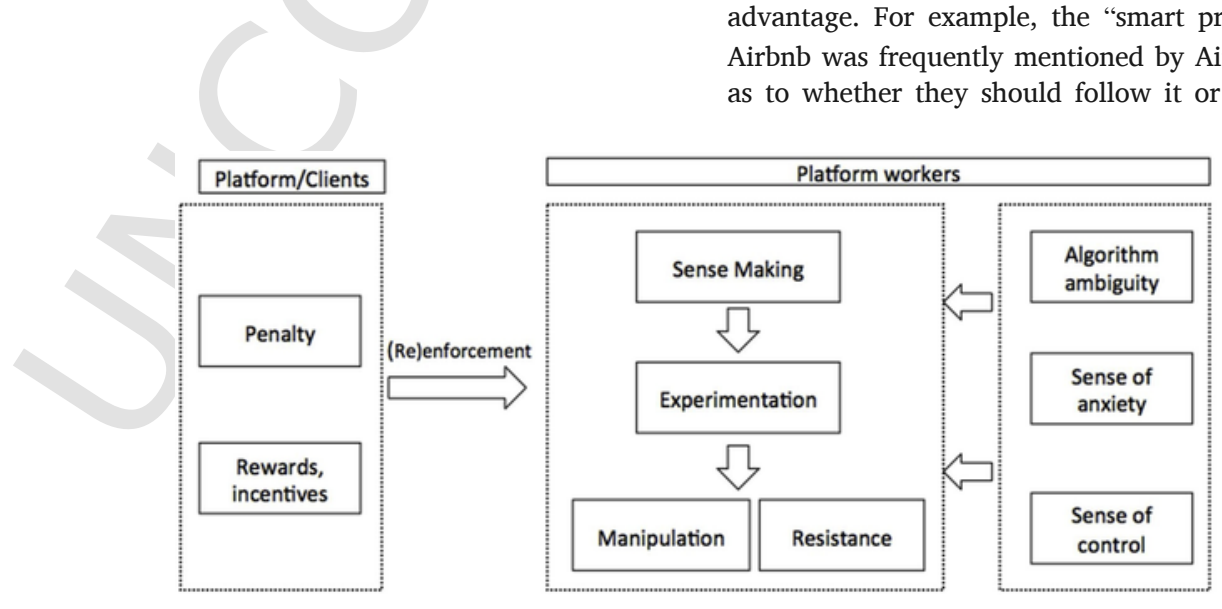

Fig. 1. Responding and adapting process of Airbnb hosts. 
generated from the algorithm gave them poor strategies. By working through a sense-making process, many Airbnb hosts started experimenting and expanding their understanding of the algorithms. For example, by decreasing the number of times they declined guests, more frequently changing their listing description, and adding the instant booking function they were able to improve business outcomes. However, most Airbnb hosts implemented these strategies intuitively, with little information and much anxiety. Further, it could be argued that Airbnb were using these algorithmic functions to exercise control over the actions of the hosts.

When strategies worked, it increased the hosts' sense of control of their Airbnb "businesses" and Airbnb hosts were encouraged to continue manipulating the system; when strategies failed, sense of control decreased and anxiety increased. In some cases Airbnb hosts chose to resist adapting their behaviours and to ignore "what Airbnb penalizes and rewards". It is important to recognise that many of the $\mathrm{n}$ (na) $\mathrm{y}$ and rewards attached to Airbnb's algorithm may represent effers oy the organisation to support Airbnb hosts to improve the business performance of their properties by attracting more Airbnb guests.

\section{Discussion and conclusion}

In sharing economy enterprises, including Airbnb, workers are increasingly required to navigate the algorithms embedded in their business context as users of the platforms. The data analysed for this study indicates that Airbnb hosts have many complaints about the lack of information, clarity and transparency available for them to navigate Airbnb algorithms. In many cases this led to a decrease in sense of control and an increase in anxiety for the hosts.

Information asymmetry between corporates and their labour force in the context of algorithms has been identified as a problem in other sharing economy contexts (Rosenblat and Stark, 2016) and does not seem to have been actively addressed by Airbnb at the time of writing. Arguably, the failure to provide their labour force with adequate information for navigating complex algorithms provides Airbnb with greater control of the business of the platform and reduces possibilities for hosts to "game the system" (Lee, 2016 is guarded approach may increase opportunities for sharing econor atforms to control certain behaviours and achieve goals. For example, Airbnb has been under considerable pressure to curb the digital discrimination practices of hosts who reject guests based on attributes such as race (Cheng and Foley, 2018) and algorithms reported by hosts (see Table 1 ) that penalise those who decline guest requests may be attributable to this goal.

On the other hand, clear and adequate information on the algorithmically generated rewards and penalties attached to particular behaviours may encourage better compliance with platform missions and goals. Greater transparency may reinforce Airbnb hosts' collective cooperation with Airbnb as well as supporting individual hosts to adopt better work strategies and to engage in ongoing learning and development in their workplace (Lee et al., 2015).

Of particular concern is the finding that indicates "Airbnb's algorithms don't favor who use the dispute resolution system". On face value, a dispute re 2 ion system would appear to be a crucial management tool in the context of a sharing economy platform that orchestrates formal exchanges between hosts and guests. If a reduction in the use of the dispute resolution system is a goal for Airbnb then this would call for more explanation than is currently available to their labour force. If it is a misconception then it would seem clear that greater transparency would benefit all involved.

The findings indicate that many Airbnb hosts were willing and able to experiment, manipulate and make sense of the algorithm, which, as a consequence, provided them with skills and experience to develop their "algorithmic competency". Algorithmic competency has been described as "a source of personal competitive [advantage allowing platform workers to]...distinguish themselves from thousands of online workers competing for the same type of projects" (Jarrahi and Sutherland, 2018, p. 5). It would be interesting to examine how algorithmic competency is evolving in sharing economy workforces and how the sharing economy platforms respond to this competency. Further, there is a risk that algorithmic competency might lead to an algorithmic divide; those who do not develop the competency may become significantly disadvantaged (Lee et al., 2015) and this warrants further investigation.

This study shows that some Airbnb hosts question the validity of the algorithms, which appears to be preventing them from adapting to the recommended strategies of the algorithms. Further, questioning the validity of algorithms may lead to an erosion of the overall credibility of sharing economy organizations. This suggests that sharing economy platforms may need to raise their accountability to encourage the behaviour they desire while maintaining algorithmic power. At this stage it is unknown whether Airbnb hosts' responses have been fed back into Airbnb algorithms. However, there does not appear to be any coordinated response from Airbnb to alleviate the concerns of hosts. The data collected from the Airbnb host forum represents a "form of fragmented social sensemaking where there were many active contributors but no central authority figure to synthesize different ideas and narratives into a coherent story" (Lee et al., 2015, p. 1611).

Ways to keep the "human-in-the-loop" is a promising area for sharing economy platform algorithm research. Indeed, the algorithm management in the sharing economy "problematizes accompanying narratives of provider agency, autonomy, and self-determination" (Newlands et al., 2018, p. 130). The findings of this exploratory study are not definitive but rather present an early understanding of an algorithmic management for users of a sharing economy platform in the accommodation sector. Therefore, we invite future researchers to unpack the algorithmic turn in tourism and hospitality in great depth.

\section{References}

Airbnb, 2018. About Us. Retrieved from https://press.airbnb.com/en-uk/about-us/.

Cheng, M., Foley, C., 2018. The sharing economy and digital discrimination: the case of Airbnb. Int. J. Hosp. Manage. 70, 95-98. https://doi.org/10.1016/j.ijhm.2017.11. 002

Foucault, M., 2012. Discipline and Punish: the Birth of the Prison. Vintage, New York.

Hookway, N., 2008. 'Entering the blogosphere': some strategies for using blogs in social research. Qual. Res. 8 (1), 91-113. https://doi.org/10.1177/1468794107085298.

Jarrahi, M.H., Sutherland, W., 2018. algorithmic management and algorithmic competencies: understanding and appropriating algorithms in gig work. Washington. . Paper Presented at the Lecture Notes in Computer Science Iconference 2019

Jhaver, S., Karpfen, Y., Antin, J., 2018. Algorithmic anxiety and coping strategies of airbnb hosts. Paper Presented at the Proceedings of the 2018 CHI Conference on Human Factors in Computing Systems.

Kozinets, R.V., 2010. Netnography: Doing Ethnographic Research Online. Sage, London.

Lee, M.K., 2016. Algorithmic bosses, robotic colleagues: toward human-centered algorithmic workplaces. XRDS: Crossroads, The ACM Magazine for Students, vol. 23, 42-47, (2).

Lee, M.K., Kusbit, D., Metsky, E., Dabbish, L., 2015. Working with machines: the impact of algorithmic and data-driven management on human workers. Paper Presented at the In Proceedings of the 33rd Annual ACM Conference on Human Factors in Computing Systems.

Mkono, M., 2018. Troll alert!': Provocation and harassment in tourism and hospitality social media. Curr. Issues Tour. 21 (7), 791-804.

Mohlmann, M., Zalmanson, L., 2017. Hands on the wheel: navigating algorithmic management and uber drivers' autonomy. Paper Presented at the Proceeding of the International Conference on Information Systems, Seoul.

Newell, S., Marabelli, M., 2015. Strategic opportunities (and challenges) of algorithmic decision-making: A call for action on the long-term societal effects of 'datification'. J. Strateg. Inf. Syst. 24 (1), 3-14.

Newlands, G., Lutz, C., Fieseler, C., 2018. Algorithmic Management in the Sharing Economy. Academy of Management Global Proceedings, 130, 2018.

Rosenblat, A., Stark, L., 2016. Algorithmic labor and information asymmetries: a case study of Uber's drivers. Int. J. Commun. 10, 3758-3784.

Strauss, A.L., Corbin, J., 1998. Basics of Qualitative Research: Techniques and Procedures for Developing Grounded Theory, 2 ed. Sage, Thousand Oaks, CA.

Yu, H., Miao, C., Chen, Y., Fauvel, S., Li, X., Lesser, V.R., 2017. Algorithmic management for improving collective productivity in crowdsourcing. Sci. Rep. 7 (1), 12541. 